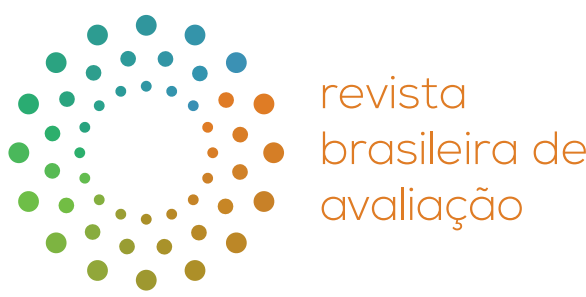

\title{
Para decolonizar a avaliação: uma análise crítica a partir da teoria da decolonialidade
}

\author{
To decolonize evaluation: a critical analysis from the theory of \\ decoloniality
}

Antônio Ribeiro ${ }^{1}$ [Branco] $\mathbb{C}$, Max Felipe Vianna Gasparini ${ }^{1 *}$ [Branco] 미

${ }^{1}$ Move Social, São Paulo, SP, Brasil

COMO CITAR: Ribeiro, Antônio,\& Gasparini, Max Felipe Vianna (2021). Para decolonizar a avaliação: uma análise crítica a partir da teoria da decolonialidade. Revista Brasileira de Avaliação, 10(1), e100621. https:// doi.org/10.4322/rbaval202110006

\section{Resumo}

Ainda que a avaliação possa ser hoje considerada uma prática mais plural e dotada de certa diversidade de abordagens e perspectivas que buscam dirimir as assimetrias de poder implicadas em seu processo, é possível afirmar que, de modo geral, as práticas avaliativas estão majoritariamente ancoradas em um discurso dominante da epistemologia da modernidade europeia. Se por um lado há movimentos de críticas aos modelos tradicionais, é possível afirmar que há insuficiente emprego de aportes teóricos conceituais críticos originais em nosso país sendo usados para compreender as implicações de nossa dependência do pensamento anglo-americano no campo da avaliação. Propomos aqui um esforço inicial que busca justamente apresentar um referencial teórico com o qual seja possível reforçar esse processo de crítica: a perspectiva teórica da decolonialidade. Concluímos provocando o debate e tecendo algumas recomendações que podem inspirar e apoiar avaliadores/as (profissionais ou não) a desenvolver uma consciência decolonial para suas práticas avaliativas.

Palavras-chave: Avaliação de programas. Decolonialidade. Epistemologia.

\section{Abstract}

Although evaluation today can be considered a more plural practice with a certain diversity of approaches and perspectives that seek to address power asymmetries involved in its process, it is possible to state that, in general, evaluation practices are mostly anchored in a dominant discourse of the epistemology of European modernity. If there are movements of criticism of traditional models, it is possible to affirm, on the other hand, that there is insufficient use of critical conceptual inputs from our country being used to understand the implications of our dependence on Anglo-American thinking in the field of evaluation. We propose here an initial effort that seeks precisely to present a theoretical reference with which to reinforce this process of criticism: the theoretical perspective of decoloniality. It concludes by provoking debates and weaving some recommendations that can inspire and support evaluators (professional or not) to develop a decolonial conscience for their evaluation practices.

Keywords: Program Evaluation. Decolonization. Epistemology.
Recebido: Outubro 29, 2020 Aceito: Dezembro 18, 2020

*Autor correspondente: Max Felipe Vianna Gasparini E-mail: maxgasparini89@gmail.com

\section{(c) BY}

Este é um artigo publicado em acesso aberto (Open Access) sob a licença Creative Commons Attribution, que permite uso, distribuição e reprodução em qualquer meio, sem restrições desde que o trabalho original seja corretamente citado. 


\section{Introdução}

A avaliação de programas emerge como prática social na confluência entre a pesquisa acadêmica e seus métodos aplicados à mensuração de comportamentos, habilidades e desempenho no campo educacional e a expansão do investimento público em políticas sociais para o desenvolvimento. A emergência da avaliação se dá notadamente na área educacional no contexto norte americano, que se inicia ainda no período de implementação do New Deal no governo de Franklin D. Roosevelt, mas se consolida a partir da década de 1960 (Worthen et al., 2004). Impulsionada pelo contexto histórico do pós segunda guerra mundial e pela corrida por influência geopolítica e tecnológica da guerra fria, as atividades de mensuração e julgamento dos resultados obtidos a partir da aplicação de volumosos recursos públicos em áreas estratégicas para o desenvolvimento do país e competição com outras potências globais, tanto no plano político-econômico quanto no plano ideológico, a avaliação passa a ganhar maior impulso e investimento neste período nos EUA. É neste processo que se estrutura as bases daquilo que viria a ser a program evaluation como a conhecemos atualmente. Desde sua gênese social marcada pela confluência do campo burocrático representado pelo Estado, e do campo acadêmico, representado pelos agentes oriundos das universidades, a avaliação de programas passou a se desenvolver aglutinando um conjunto de desafios práticos e metodológicos e disputas de narrativas em torno de suas bases científicas e políticas. Essas disputas se inserem em um contexto mais amplo em torno da dimensão do poder associado às práticas avaliativas já chanceladas por um Estado poderoso como o norte-americano e revestida de impenetrável aura de legitimidade do discurso científico pelos aportes que a academia e seus agentes traziam para a avaliação.

A questão em torno do poder na prática da avaliação está relacionada a muitas dimensões que podem ser abordadas a partir de distintas matrizes analíticas. Podemos abordar essa discussão flanqueando as definições em torno de quem avalia, como se avalia e o que se avalia. A determinação sobre quem possui a legitimidade para julgar um dado objeto se associa ao como fazê-lo "adequadamente", ou as formas como se operacionalizam as avaliações. Essa tríade se completa com a decisão em torno dos objetos avaliados, ou o que se pode/deve julgar. Essas e outras questões foram discutidas nas diversas produções teóricas da avaliação ao longo de seu desenvolvimento, sendo possível identificar processos de rupturas e permanências com estruturas de poder que envolvem a prática da avaliação. Guba \& Lincoln (1989), ao proporem a abordagem da avaliação de quarta geração situam-na enquanto uma resposta às abordagens de gerações anteriores, fortemente pautadas pelo paradigma epistemológico do positivismo lógico e incapazes de lidar com a complexidade dos objetos avaliados e com a pluralidade de atores implicados, além de ignorar fatores políticos e ideológicos da avaliação, o que aprofundava ainda mais as relações de dominação inscritas nos processos avaliativos. O componente participativo e o foco na interpretação dos diferentes sentidos que os agentes conferem a sua experiência emergem enquanto elemento central nesta abordagem de avaliação, relativizando assim o poder atribuído aos avaliadores e os métodos científicos empregados (Guba \& Lincoln, 1989).

Outras propostas de abordagens em avaliação buscaram igualmente romper ou minimizar os mecanismos de poder que operam no interior da avaliação e seus desdobramentos na reprodução de assimetrias nas relações sociais. Vedung (2010), por exemplo, identifica um tipo de tendência no campo chamada por ele de avaliações orientadas pelo diálogo (The Dialogue-Oriented Wave), que emergem a partir das críticas aos enfoques da avaliação orientada pela racionalidade científica tradicional e a verticalidade de sua condução, que envolviam somente administradores superiores e especialistas ligados à academia em detrimento de outros públicos interessados nas intervenções avaliadas, como seus beneficiários (Vedung, 2010). Por sua vez, House (2004) irá problematizar o papel de quem avalia em um contexto em que as premissas da avaliação são cada vez mais normatizadas por interesses políticos e disputas por poder. $\mathrm{O}$ autor chama a atenção para o fato de que as pessoas que avaliam deveriam estar atentas para as implicações e pressões políticas sobre os processos avaliativos, buscando manter uma independência em relação aos interesses de gestores ou demais grupos envolvidos, sendo este fator fundamental para se produzir avaliações mais democráticas e participativas. House (2004) formula uma proposta de avaliação pautada em um processo 
dialogado que busque balancear os diferentes interesses e valores de todas as partes envolvidas numa determinada intervenção: a chamada Avaliação Democrática Deliberativa (Deliberative Democratic Evaluation), que se fundamenta em três princípios gerais: 1) a inclusão de todas as informações relevantes e opiniões dos interessados, seus valores e interesses na avaliação; 2) garantia de um espaço de extenso diálogo entre quem avalia e demais grupos envolvidos, buscando o entendimento mútuo; e 3) deliberação feita por todas as partes para ajudar a alcançar conclusões válidas.

Ainda no contexto de abordagens alternativas aos enfoques mais tradicionais, podemos localizar nas práticas e reflexões oriundas do campo da saúde importantes contribuições para este debate. Os chamados enfoques emergentes de avaliação de programas em saúde têm se consolidado enquanto alternativas aos modelos tradicionais e hegemônicos a partir de um conjunto de críticas de caráter epistemológico, metodológico, ético e político (Mercado \& Bosi, 2006). A abertura propiciada pela avaliação responsiva desenvolvida por Robert Stake (1975) foi essencial para o desenvolvimento de abordagens avaliativas centradas nas preocupações e nos problemas dos grupos participantes neste campo. Vem de Stake (1975) a preocupação da avaliação se estruturar a partir da interação e comunicação com os grupos de interesse, no sentido de propiciar uma compreensão ampliada do objeto avaliado a partir e para estes públicos (Stake, 1975; Worthen et al., 2004).

No Brasil e na América Latina, a profusão de diferentes enfoques emergentes da avaliação de programas, com importante contribuição do campo da saúde, vem acompanhada do uso de diferentes nomenclaturas, como avaliações construtivistas e participantes (Furtado, 2001), democráticas, críticas, qualitativas, de baixo para cima, colaborativas, deliberativas, dialógicas, entre outras (Mercado \& Bosi, 2006). O referencial teórico da avaliação de quarta geração tem sido utilizado, como atestam as publicações no campo da saúde (Kantorsk et al., 2011; Wetzel, 2005; Campos et al., 2009; Schneider et al., 2009; Gasparini \& Furtado, 2019).

Há movimentos sendo desenvolvidos no interior do campo da avaliação que buscam problematizar a dependência teórica e a colonização epistemológica dos modelos de avaliação advindos do norte global. Assim como na América Latina, tem sido observado expressivo aumento e institucionalização da avaliação no continente africano, impulsionado pela necessidade de avaliar os impactos dos investimentos sociais e humanitários de muitos doadores e investidores naquela região. Hoje compreende-se que as bases que sustentam os modelos de avaliação praticadas na África, assim como na América Latina, seguem os padrões estabelecidos pela episteme europeia colonizadora, com desdobramentos para a definição de métodos e enfoques privilegiados. O movimento de indigenização do conhecimento na África tem buscado compreender as dinâmicas de reprodução destes valores e descolonizar a avaliação da episteme europeia, trazendo para o centro do debate o conjunto de conhecimentos e valores culturais de raízes africanas para subsidiar a avaliação e torná-la mais relevante para o contexto específico deste continente (Tirivanhu \& Mapitsa, 2019).

A partir da discussão em torno das implicações do modelo hegemônico de avaliação advindo das exigências das agências multilaterais para a mensuração dos impactos dos investimentos realizados no Brasil, são importantes também as elaborações que buscam remodelar a prática e a reflexão da avaliação realizada por aqui, como a reorientação de referências observada em balanço atual sobre a produção de pesquisas avaliativas realizadas no âmbito do programa de pós-graduação de uma universidade pública do nordeste brasileiro (Gussi, 2019). Observa-se neste estudo de caso o crescimento de avaliações cujo componente epistemológico busca superar os limites de modelos hegemônicos a partir dos aportes da avaliação em profundidade, que privilegia uma abordagem interpretativa, a contextualização e a consideração das trajetórias institucionais para avaliação de políticas públicas (Gussi, 2019).

A despeito do crescente interesse e desenvolvimento de experiências práticas e reflexões críticas, persistem desafios de distintas ordens no que se refere à avaliação sob os enfoques alternativos, como analisado por Mercado et al. (2006). O referido estudo aponta para desafios a serem superados no que tange à dimensão teórico-conceitual, política, metodológica e ao uso dos resultados das avaliações, além de uma falta de cruzamento entre os referenciais locais, mantendo uma dependência com outros autores, principalmente os anglo-saxões e os 
norte-americanos (Mercado et al., 2006). Como visto, muitas críticas e tentativas de superação de modelos mais tradicionais e verticais são oriundos de autores que produzem a partir de suas experiências no norte global, o que implica no enraizamento de seus discursos em questões típicas de seus contextos políticos, institucionais e ideológicos. Ao proporem caminhos para avaliações mais democráticas, por exemplo, não é razoável supor que os desafios políticoinstitucionais latino-americanos e africanos e aqueles presentes nas democracias do norte apresentam a mesma natureza de desafios e soluções passíveis de serem transportadas para nosso contexto acriticamente.

Ainda que a avaliação possa ser hoje considerada uma prática mais plural e dotada de certa diversidade de abordagens e perspectivas avaliativas que buscam dirimir as assimetrias de poder implicadas em seu processo, é possível afirmar que, de modo geral, as práticas avaliativas estão majoritariamente ancoradas em um discurso dominante da epistemologia da modernidade europeia. Não obstante a profusão de experiências práticas publicadas e as formulações de origem latino americanas, operamos ainda majoritariamente a partir do arcabouço teórico de referências consagradas no campo da avaliação, originários do norte global, cuja capacidade de se reinventar e manter seu discurso de dominação se mostra cada vez mais efetivo.

Se por um lado há movimentos de críticas aos modelos tradicionais, é possível afirmar que há insuficiente emprego de aportes teóricos conceituais críticos originais de nossa região sendo usados para compreender as implicações de nossa dependência com o pensamento angloamericano no campo da avaliação. Propomos aqui um esforço inicial que busca justamente apresentar um referencial teórico com o qual seja possível reforçar esse processo de crítica. Trata-se da perspectiva teórica da decolonialidade.

\section{Os estudos decoloniais}

Os chamados estudos decoloniais surgem como movimento e proposta investigativacrítica no final da década de 1990, centralmente a partir das pesquisas de Aníbal Quijano (1928-2018), sociólogo peruano nascido na província de Yungay, acerca da colonialidade do poder. Referindo-se ao alcance da teoria proposta por Quijano, Segato (2014) afirma que o pensamento do autor compõe uma das únicas quatro teorias originadas em solo latino americano que, entre diversas outras, conseguiram cruzar bloqueios e reservas políticointelectuais, rumando potentes e contundentes ao norte, em um consumo de sentido reverso. Dentro desta perspectiva ela estaria ao lado da Teologia da Libertação (cujo peruano Gustavo Gutierrez é a principal referência inicial), da Pedagogia do Oprimido (tendo o brasileiro Paulo Freire como porta voz) e da Teoria da Marginalidade (reconhecida na autoria do argentino José Nun).

Os estudos sobre a colonialidade do poder ou decolonialidade que se originam com, e a partir de, Quijano se dedicam à questão do poder na modernidade, tendo em comum um conjunto de proposições que buscam desmistificar o discurso dominante que sustenta os empreendimentos europeus a partir do século XV enquanto pilares de uma civilidade avançada e moderna. Desta forma, a decolonialidade começa sua desconstrução ideológica justamente ao inverter uma série de discursos que servem ao propósito de conservar as relações de poder instituídas desde as origens do chamado período da modernidade com o controle do Atlântico pelas potências marítimas da Europa, e não pelas obras e invenções do lluminismo ou da Revolução Industrial, como é comumente reproduzido no discurso dominante (Quintero et al., 2019). Essa desconstrução dá ênfase ainda às formas de estruturação do poder por meio do colonialismo e das dinâmicas que constituem o sistema capitalista na modernidade e suas formas de acumulação e exploração do trabalho em escala global, que por sua vez produziram uma organização global assimétrica. Este processo ideológico de dominação encontra ao menos dois eixos estruturais: o controle do trabalho e suas relações e da intersubjetividade, constituindo um cenário de subalternização da maioria da população mundial (Quintero et al., 2019). O discurso advindo da narrativa europeia ocidental dominante serviu ao propósito de justapor seus empreendimentos e projetos (político, científico, social, econômico, ideológico) ao conceito dominante de civilização moderna, e designou o "[...] eurocentrismo/ocidentalismo 
como a forma específica de produção de conhecimento e subjetividades na modernidade" (Quintero et al., 2019).

\section{O eurocentrismo, a "modernidade" e a colonialidade do poder}

O eurocentrismo costuma ser definido como sendo o movimento de influência política, cultural, econômica e epistêmica, empreendido por países da Europa de modo mais contundente a partir do século XVI. Segundo Quijano (2014) alguns traços centrais podem caracterizar a perspectiva epistemológica eurocêntrica sob a qual se apoiam ações, narrativas e muitos outros aparatos, sendo eles: a) o dualismo radical que separa sujeito e objeto do conhecimento, proveniente dos constructos cartesianos, no qual o sujeito é indeterminado, não situado e, portanto, universal, e o objeto é algo independente do sujeito e das relações e representações que entrelaçam este sujeito, podendo se mostrar tal como é; b) a separação entre razão e natureza (europeus e mundo), derivada da objetividade do conhecimento e do mundo (visto então como diferente do sujeito, homem, europeu, branco), que fundamenta e autoriza a exploração desmedida desta natureza para fins produtivos e econômicos, suportando ainda a instalação da ideia de raça como algo natural; c) a concepção compartimentada que institui âmbitos e contornos diferenciados para a vida social e os maneja a partir de referências e termos organicistas e funcionalistas; d) o evolucionismo, que entende a sociedade como realidade homogênea que "avança, inevitavelmente e de maneira unilinear e unidirecional até o progresso" racional, técnico e/ou religioso, e que vai adicionar e reforçar hierarquias à ideia de raça" (Germaná, 2014 p.88).

O eurocentrismo passa a determinar um referencial epistêmico, localizado, a partir do qual se constrói um "modelo de conhecimento que, por um lado, universaliza a experiência local europeia como modelo normativo a seguir e, por outro, designa seus dispositivos de conhecimento como os únicos válidos" (Quintero et al., 2019, p. 7). Sobrepõe (e impõe) uma modernidade em detrimento de várias outras já existentes e coabitantes do sistema-mundo.

Se o conceito de modernidade refere-se única ou fundamentalmente às idéias de novidade, do avançado, do racional-científico, laico, secular, que são as idéias e experiências normalmente associadas a esse conceito, não cabe dúvida de que é necessário admitir que é um fenômeno possível em todas as culturas e em todas as épocas históricas. Com todas as suas respectivas particularidades e diferenças, todas as chamadas altas culturas (China, Índia, Egito, Grécia, Maia-Asteca, Tauantinsuio) anteriores ao atual sistema-mundo, mostram inequivocamente os sinais dessa modernidade, incluído o racional científico, a secularização do pensamento, etc. (Quijano, 2005, p. 122)

Este novo poder mundial euro-moderno e colonial, configura um novo universo de relações intersubjetivas, centrada em uma dominação e violência física e simbólica das populações europeias sobre as demais que justificou feitos como explorações de inventos e descobrimentos culturais, repressão de modos de produção, conhecimentos e representação simbólica, assim como a aprendizagem forçada da cultura dominante (dos dominadores). Em suma, a colonialidade e as relações de poder com ela estabelecidas se traduz no mundo intersubjetivo do outro dominado (de raça inferior) e no condicionamento que nos levou, latinoamericanos, a nos vermos com os olhos do dominador (Germaná, 2014)

Podemos dizer que o eurocentrismo é uma perspectiva de conhecimento/epistêmica que se fez (e faz) mundialmente hegemônica, colonizando e sobrepondo-se a todas as demais perspectivas e moldando um sistema-mundo. Noções antropológicas (raças ${ }^{1}$ ), políticas (esquerda e direita) ou socioeconômicas (progresso e desenvolvimento), criadas em algumas mentes, de alguns países e contextos específicos há mais de cinco séculos, apoiam e endossam muitos pensamentos, debates, estruturas e atitudes ainda hoje. Ainda que a maioria destas noções mais atrapalhem do que ajudem, elas ilustram bem como o eurocentrismo se impõe e molda dinâmicas e relações na contemporaneidade.

\footnotetext{
1 Podemos afirmar ainda que eurocentrismo e racismo epistêmico não são senão dois nomes para o mesmo
} gesto colonial (Segato, 2014). 
A investigação da tríade modernidade, colonialidade e decolonialidade, são assim constituintes dos estudos decoloniais em uma perspectiva transdisciplinar que transcende, como dito, a América Latina e se une a movimentos e correntes teórico-práticas de resistência ao pensamento e episteme eurocentrada e branca da qual decorrem opressões, violências e abusos de diferentes naturezas. Mas cabe dizer que, apesar de advir de um lugar e perspectiva latinoamericana, esta teoria não se aplica e limita apenas ao nosso território e o que aconteceu e acontece aqui. A partir da compreensão e questionamento de um poder globalmente hegemônico, é possível provocar uma nova leitura da história mundial e o que se costuma chamar de um giro decolonial, que em alusão ao giro copernicano, leva a uma mudança sem voltas na percepção sobre a realidade, remodelando o sistema-mundo (Segato, 2014).

\section{O giro decolonial}

Compreender criticamente esta construção eurocentrada, norte-orientada e seus desdobramentos, opressões e limites, ao mesmo tempo reconhecendo, valorizando e operando outras epistemes, modernidade e mundos, é o que está no cerne da perspectiva da decolonialidade, ou descolonialidade. Essa atitude expressa resistência, questionamento e busca por mudar padrões do ser, do saber e do poder (Maldonado-Torres, 2007), representando o chamado giro decolonial em alusão a um movimento de inversão de um fluxo unidirecional imposto e instalado de forma natural. É, portanto, uma subversão epistêmica do poder, que é também teórica, ética, estética e política. Uma "reorientação da posição do sujeito em um novo plano histórico, emergente de uma releitura do passado, que reconfigura o presente e tem como projeto uma produção democrática de uma sociedade democrática" (Segato, 2014, p. 59)

Esta inflexão da qual trata a decolonialidade do poder e seu giro decolonial, por surgirem na periferia do sistema-moderno/colonial, pode ser compreendida como uma perspectiva ou um pensamento fronteiriço, que afronta (se põe frente a frente) a um pensamento eurocêntrico que, como vimos, tem estado aprisionado em uma ideia de progresso inevitável, levado adiante pelo desenvolvimento das forças produtivas e por uma luta de classes que a expressa (Germaná, 2014).

Algumas perspectivas não europeias têm ocupado um espaço importante em um recente giro decolonial coletivo, oferecendo outras noções e visões sobre e para o sistema-mundo, dentre as quais se destacam o Bem Viver e o Ubuntu. A primeira é apoiada em uma modernidade/ episteme dos povos andinos da América Latina e advém da expressão suma qamaña em quechua/quichua, e a segunda em uma modernidade/episteme de povos do sul do continente africano, advinda em uma de suas formas da expressão umuntu ngumuntu ngabant, em Zulu.

Embora não entremos aqui em um detalhamento sobre estas duas visões, cabe marcar a influência que o Bem Viver (Buen Vivir) tem exercido na produção de muitas/os "decolonialistas" latino americanos, pautando propostas alternativas deste grupo à colonialidade do poder. Sua orientação se volta a refazer a vida socioambiental a partir da solidariedade humana e com a natureza, não só na atividade econômica e produtiva, senão em todas as dimensões da existência social: o trabalho, o sexo, a autoridade coletiva, a subjetividade e a natureza. Nesta medida, o Bem Viver é uma ruptura com o eurocentrismo e a produção de conhecimento (Pimentel, 2014).

O próprio Quijano, bastante inspirado pela perspectiva do Bem Viver, afirma que para consolidar-se, a descolonialidade do poder implicaria práticas sociais configuradas por:

a) la igualdad social de individuos heterogéneos y diversos, contra la desigualizante clasificación e identificación racial/sexual/social de la población mundial; b) por consiguiente, las diferencias, ni las identidades, no serían más la fuente o el argumento de la desigualdad social de los individuos; c) las agrupaciones, pertenencias y/o identidades serían el producto de las decisiones libres y autónomas de individuos libres y autónomos; d) la reciprocidad entre grupos y/o individuos socialmente iguales, en

\footnotetext{
2 Tradução livre dos autores.
} 
la organización del trabajo y en la distribución de los productos; e) la redistribución igualitaria de los recursos y productos, tangibles e intangibles, del mundo, entre la población mundial; f) la tendencia de asociación comunal de la población mundial, en escala local, regional, o globalmente, como el modo de producción y gestión directas de la autoridad colectiva y, en ese preciso sentido, como el más eficaz mecanismo de distribución y redistribución de derechos, obligaciones, responsabilidades, recursos, productos, entre los grupos y sus individuos, en cada ámbito de la existencia social, sexo, trabajo, subjetividad, autoridad colectiva y co-responsabilidad en las relaciones con los demás seres vivos y otras entidades del planeta o del universo entero (Quijano, 2014, p. 30).

\section{À guisa de conclusão: para decolonizar a avaliação}

Como dito no início deste ensaio, a avaliação praticada no contexto brasileiro e latinoamericano (bem como, entre outros territórios, no continente africano) tem como referencial teórico central as produções formuladas no norte global, que ao serem transpostas e assimiladas em nosso contexto carregam as propriedades discursivas dominantes de uma episteme europeia ocidental. Como abordado pela teoria da decolonização, esse discurso que carrega os elementos simbólicos e materiais históricos da relação colonizador/colonizado tem produzido assimetrias, exclusão e dominação nos diversos contextos socioculturais onde é reproduzido, perpetuando o rebaixamento de grandes contingentes populacionais em seus territórios a papéis subalternos no sistema global. Desde as injustiças em relação às formas e enquadres de compreensão das iniciativas avaliativas até o exercício do poder político em avaliações que segregam e oprimem muitas vezes de forma velada, são muitas as formas de dominação nas quais a avaliação, assim como outras práticas sociais, se encontra entremeada.

Uma contribuição central do pensamento de Quijano é a compreensão de que a colonialidade opera como uma estrutura de poder que se mantém mesmo após o término formal do processo de dominação colonial, e que tem a capacidade de reinventar e reproduzir-se no tempo. A avaliação não é uma prática neutra que escapa a essa dominação, servindo-a à medida em que modelos pré-formatados de enquadre das realidades complexas e culturalmente significantes são aplicados e operam verdadeiro "saneamento" da complexidade dos contextos, das contradições, das ambiguidades e das relações de dominação, agindo, portanto, enquanto mecanismo - ela mesma - de dominação.

Não temos a pretensão de estabelecer neste ensaio uma proposta pronta de enunciados decoloniais para a avaliação, mas antes buscar estimular e engajar mais pessoas que praticam avaliação a ir além neste debate a partir do referencial teórico apresentado. Contudo, à luz das leituras, escutas e debates empreendidos, arriscamos aqui registrar, sucintamente e provocando o debate, algumas recomendações que podem inspirar/apoiar avaliadores/ as (profissionais ou não) a desenvolver uma consciência decolonial (ciente das dinâmicas operantes na colonialidade do poder) para sua prática avaliativa:

a. Não mais usarmos a participação, sob o discurso da escuta limitada a mera obtenção de informação, como forma de manipulação e desprovida de real implicação dos públicos nas tomadas de decisão.

b. Deixarmos de fazer uma aplicação acrítica e descontextualizada de modelos e planos de avaliação pré-formatados, fechados e importados diretamente dos escritórios de investidores, cujas matrizes e indicadores atendem às expectativas das altas lideranças e correspondem a uma determinada concepção de qualidade e desenvolvimento. Usados enquanto réguas para medir o desempenho das iniciativas, esses modelos acabam por impor padrões e moldam julgamentos de insuficiências e inadequações que reforçam o discurso de que os contextos são sempre problemáticos diante de intervenções cuidadosamente planejadas e geridas. A avaliação passa a estar assim a serviço de uma lógica colonizadora que, por meio de iniciativas de apoio para o desenvolvimento e emprego de instrumentos "racionais" para adequação destas iniciativas mantém operando o discurso de um norte civilizado, racional e próspero e um sul caótico, desorganizado e ineficiente em si mesmo. 
c. Buscarmos uma prática que, como diz Maldonado-Torres (2016), cria laços e novas formas entre "esferas que a Modernidade ajudou a separar: a esfera da política ou do ativismo social, a esfera da criação artística e a esfera da produção de conhecimento". A partir desta consciência decolonial nos proporíamos a mais formas de atuar, de ser e de conhecer constituídas nos encontros entre áreas como estas. E é o fronteiriço do pensamento decolonial que provoca esse caráter transdisciplinar que, acreditamos, pode orientar também as avaliações.

d. Nutrirmos mais debates e incidirmos intencionalmente, como facilitadores e facilitadoras do processo avaliativo, sobre temas e pontos que toquem o racismo estrutural e outras formas de dominação, opressão e exclusão. Podemos trazer e inserir categorias de construção e análise de dados, garantir representação, convergência com manifestos de grupos e povos oprimidos e não privilegiados, entre outras possibilidades. Nessa esteira, podemos afirmar aqui que uma avaliação decolonialista precisa ser necessariamente uma avaliação antirracista.

Buscamos mostrar que o referencial da decolonização em conjunto com outras elaborações decoloniais podem nos oferecer subsídios para cada vez mais desnaturalizar a prática avaliativa enquanto uma prática neutra, racional e movida apenas pela busca do bem estar e do desenvolvimento. O caminho da libertação em relação à colonialidade certamente passará por avaliadores e avaliadoras críticos e capazes de agir a partir de um pensar atento e de avaliações fortemente contextualizadas, democráticas e sensíveis aos diferentes contextos sócio-culturais e as formas originais de pensar e estar no mundo dos povos historicamente dominados.

\section{Fonte de financiamento}

Não há.

\section{Conflito de interesse}

Não há.

\section{Agradecimentos}

Agradecemos à Tânia Crespo pelo diálogo, disponibilidade e partilha de reflexões que ajudaram na revisão final deste ensaio.

\section{Referências}

Furtado, Juarez Pereira. (2001). Um método construtivista para a avaliação em saúde. Ciência \& Saúde Coletiva, 6(1), 165-181. http://dx.doi.org/10.1590/S1413-81232001000100014.

Gasparini, Max Felipe Vianna, \& Furtado, Juarez Pereira. (2019). Longitudinalidade e integralidade no Programa Mais Médicos: Um estudo avaliativo. Saúde em Debate, 43(120), 30-42. http://dx.doi. org/10.1590/0103-1104201912002.

Germaná, César. (2014). Una epistemología otra: La contribución de Aníbal Quijano a la reestruturación de las Ciencias Sociales de América Latina. In Aníbal Quijano (Ed.), Des/colonialidad y bien vivir: un nuevo debate en América Latina (pp. 73-101).Peru: Universidad Ricardo Palma. Editorial Universitaria.

Guba, Egon G, \& Lincoln, Yvonna S. Fourth Generation Evaluation, Newbury Park: Sage, 1989.

Gussi, Alcides Fernando. (2019). Outras epistemologias e metodologias: a experiência do Mestrado de Avaliação de Políticas. Públicas Revista Aval, 2(16), 168-183.

House, Ernest R. (2004). The role of the evaluator in a political world. The Canadian Journal of Program Evaluation, 19(2), 1-16.

Kantorski, Luciane Prado, Coimbra, Valéria Cristina Christello, Silva, Emília Nalva Ferreira da, Guedes, Ariane da Cruz, Cortes, Jandro Moraes, \& Santos, Fernanda dos. (2011). Avaliação qualitativa de ambiência num Centro de Atenção Psicossocial. Ciencia \& Saude Coletiva, 16(4), 2059-2066. PMid:21584447. http:// dx.doi.org/10.1590/S1413-81232011000400005

Maldonado-Torres, Nelson. (2007). Pensamiento crítico desde la sub-alteridad: los estudios étnicos como ciencias descoloniales o hacia la transformación de las humanidades y las ciencias sociales en el siglo veintiuno. In: Saavedra, José Luis (Ed.), Educación superior, interculturalidad y descolonización (pp. 145-174). La Paz: Programa de Investigación Estratégica en Bolivia, Comité Ejecutivo de la Universidad Boliviana. 
Maldonado-Torres, Nelson. (2016). Transdisciplinaridade e decolonialidade. Revista Sociedade e Estado, 31(1), 75-97. http://dx.doi.org/10.1590/S0102-69922016000100005.

Mercado, Francisco J; Hernández, Nereyda; Tejada, Luz María; Springett, Jane; Calvo, Ana. (2006). Avaliação de políticas e programas de saúde: enfoques emergentes na Ibero-América no início do século XXI. In: Francisco J. Mercado \& Maria Lúcia M. Bosi. Avaliação qualitativa de programas de saúde: enfoques emergentes (Orgs.), (pp. 22-62). Petrópolis, RJ: Vozes.

Mercado, Francisco J, \& Bosi, Maria Lúcia M. Avaliação não tradicional de programas de saúde: anotações introdutórias. In: Mercado, Francisco J e Bosi, Maria Lúcia M. Avaliação qualitativa de programas de saúde: enfoques emergentes (orgs.). Petrópolis, RJ: Vozes. p. 11-21. 2006.

Campos, Onocko, Furtado, Juarez Pereira, Passos, Eduardo, Ferrer, Ana Luiza, Miranda, Lilian, \& Gama, Carlos Alberto Pegolo da. (2009). Avaliação da rede de centros de atenção psicossocial: Entre a saúde coletiva e a saúde mental. Revista de Saude Publica, 43(Suppl. 1), 16-22. PMid:19669060. http://dx.doi. org/10.1590/S0034-89102009000800004

Pimentel, Boris Marañón. (2014). Buen Vivir y descolonialidad. Crítica al desarrollo y la racionalidad instrumentales. (p. 272). México D.F.: Ediciones Universidad Nacional Autónoma de México e Instituto de Investigaciones Económicas.

Quijano, Aníbal (2014). Des/colonialidad y bien vivir: un nuevo debate en America Latina. Lima: Editorial Universitaria.

Quijano, Anibal. (2005). Colonialidade do poder, eurocentrismo e América Latina. In Edgardo Lander (Org.), A colonialidade do saber: eurocentrismo e ciências sociais. Perspectivas latino-americanas (pp. 227278). Buenos Aires, Argentina: CLACSO.

Quintero, Pablo, Figueira, Patrícia, \& Elizalde, Paz Concha. (2019). Uma breve história dos estudos decoloniais. São Paulo: MASP Afterall.

Schneider, Jacó F., Camatta, Márcio Wagner, Nasi, Cintia, Kantorski, Luciane Prado, Wetzel, Christine. (2009). Utilização da avaliação de quarta geração em um centro de atenção psicossocial. Revista Gaúcha de Enfermagem, 30(1), 131-135.

Segato, Rita Laura. (2014). Aníbal Quijano y la perspectiva de la colonailidad del poder. In Aníbal Quijano (Ed.), Des/colonialidad y bien vivir: un nuevo debate en America Latina (pp. 35-71). Lima: Editorial Universitaria.

Stake, Robert. (1975). Program evaluation particulary responsive evaluation. Champaign, IL: Center for Instructional Research and Curriculum Evaluation, University of Illinois at Urbana-Champaign.

Tirivanhu, Precious, \& Mapitsa, Caitlin Blaser. (2019). Indigenising evaluation knowledge: exploring the epistemic identity of african evaluators. In: Caitlin Blaser Mapitsa, Nedson Pophiwa, \& Precious Tirivanhu. Evaluation landscape in Africa - Context, Methods and Capacity. Stellenbosch: African Sun Media. http:// dx.doi.org/10.18820/9781928480198/07.

Vedung, E. (2010). Four waves of evaluation diffusion. Evaluation, 16(3), 263-277. http://dx.doi. org/10.1177/1356389010372452

Wetzel, Christine. (2005). Avaliação de serviço em saúde mental: a construção de um processo participativo (Tese de doutorado). Escola de Enfermagem de Ribeirão Preto, Universidade de São Paulo, São Paulo. 209 f.

Worthen, Blaine R., Sanders, James R., \& Fitzpatrick, Jody L. (2004). Avaliação de programas: concepções e práticas. São Paulo: Editora Gente e Edusp. 